\title{
Complexity in the making: non-biological complex drugs (NBCDs) and the pharmacopoeias
}

\author{
Professor Gerrit Borchard, PharmD, PhD
}

Pharmacopoeias, as standard references for pharmaceutical drug specifications and reference standards in the form of monographs, play a pivotal role to assure drug quality and safety. With emphasis on the activities concerning non-biological complex drugs (NBCDs), the mechanisms by which new monographs are introduced into the European and the US pharmacopoeias are presented.

\section{Keywords: Drug quality, ICH, non-biological complex drugs (NBCDs), pharmacopoeia, Ph. Eur., USP}

\begin{abstract}
Introduction
Over the last decades we came to realize that high molecular weight drugs of biological origin, such as therapeutic antibodies, are of a highly complex structure, which determines their activity as well as safety in terms of immunogenicity. The manufacturing of such therapeutics requires highly complex and meticulously controlled up- and downstream processes. Still, the final drug product whose properties are determined by the process is characterized by a certain degree of 'microheterogeneity', i.e. the presence of several isomers of the active pharmaceutical ingredient (API).
\end{abstract}

'Follow-on' protein therapeutics will not be manufactured by the same process proprietary to the originator. As the process itself determines the properties, e.g. microheterogeneity, of the final drug product, an originator protein therapeutic and its follow-on product may not be considered to be identical. Hence, the generic principle applied for drugs of low molecular weight, whose properties and composition are well defined and can be reproduced by generic drug producers, cannot be applied to complex drugs such as therapeutic proteins. A regulatory strategy leading to marketing authorization of follow-on biologicals in Europe and by the US Food and Drug Administration (FDA) - the 'biosimilar' pathway - has thus been established and refined. This approach includes elements such as clinical testing of the follow-on against the originator product in clinical trials, as well as post-marketing surveillance [1].

Another group of complex drugs of non-biological origin (NBCDs - non-biological complex drugs) share aspects of complex structure, potential immunogenicity and impossibility of full characterization by physicochemical methods alone with biological complex drugs. Examples for these complex drugs include glatiramoids $\left(\right.$ Copaxone $\left.{ }^{\circledast}\right)$, liposomal formulations $\left.\left(D x_{i}\right)^{\oplus}\right)$ and nanoparticles such as iron-carbohydrate particles $\left(\right.$ Venofer $\left.^{\circledR}\right)$. These drugs are considered to belong to a new class of 'nanomedicines' [2]. Their size and attributes at the molecular scale confer these systems certain properties to interact with their biological environment.

Nanoscale drug delivery systems have been under investigation for several decades, yet only very few have actually matured to clinical application. While analytical techniques describing the physicochemical properties of these systems are being constantly refined, we had to understand that these systems need a multi-pronged analytical approach to describe their physicochemical properties. However, little is known on the relation between these properties and the clinical outcome, such that these systems always need clinical assessment to ensure efficacy and safety. The situation is rendered even more complex by the appearance of intended copies of NBCDs. Some of those, e.g. iron sucrose products ('iron sucrose similars, ISSs'), and 'generic' Doxil (approved by FDA in 2013 in view of drug shortages in the US) have entered the market under the generics paradigm, partially due to the absence of a more suitable regulatory evaluation process. Therefore, an effort is needed to discover these correlations between nano-properties and biological activity, develop suitable analytical techniques and define specifications, establish clinical protocols and, last but not least, integrate this knowledge in a science-based regulatory approach to nanomedicines [3].

The principle of nanomedicines being complex drugs is well established within the scientific community. Regulatory authorities are also catching up, as shown by recent activities in the field. FDA is currently sponsoring a study comparing two iron carbohydrate products (Nulecit ${ }^{\circledast}$, Ferrlecit ${ }^{\circledR}$ ) for their similarity, involving physicochemical characterization, in vitro and clinical studies [4]. The European Medicines Agency (EMA) has published a reflection paper on the subject of 'data requirements for iron-based nano-colloidal products' in February 2015, which lists a range of characterization methods for these products.

In the context of ensuring the quality and safety of medicines, pharmacopoeias, as standard references for pharmaceutical drug specifications in the form of monographs, play a pivotal role. Derived from the Greek expressions $\phi \dot{\alpha} \rho \mu \alpha \kappa o v$ (pharmakon) and $\pi$ o $\iota \hat{i} \alpha$ (making), pharmacopoeias appeared as early as $50 \mathrm{AD}$ (De Materia Media). In Great Britain, the national British Pharmacopoeia (BP) was published for the first time in 1864, the United States Pharmacopeia (USP) already in 1820. In addition to such national pharmacopoeias, international forms do exist as well and may replace national ones. The foundation for the European Pharmacopoeia (Ph. Eur.) was laid in 1964 by a convention of the Council of Europe, and the first volume of the International Pharmacopoeia (Ph. Int.) was published by the World Health Organization (WHO) in 1951.

Author: Professor Gerrit Borchard, PharmD, PhD, Professor, Biopharmaceutical Sciences, School of Pharmaceutical Sciences, University of Geneva, University of Lausanne, 30, quai Ernest-Ansermet, CH-1211 Geneva 4, Switzerland

Submitted: 15 March 2016; Revised: 22 March 2016; Accepted: 24 March 2016; Published online first: 4 April 2016 
Having the common goal to ensure access to good quality medicines, the organizational forms of these pharmacopoeias and the procedures followed to introduce new monographs differ largely. This manuscript gives an overview on such issues, and analyses the level of awareness for NBCDs at the European and US pharmacopoeias.

\section{European and US pharmacopoeias and non-biological complex drugs (NBCDs)}

1. The European Pharmacopoeia (Ph. Eur.)

The European Directorate for the Quality of Medicines and Healthcare (EDQM) is a directorate of the Council of Europe $(\mathrm{CoE})$, whose function was first defined by the 'Convention on the elaboration of a European Pharmacopoeia' [5] signed in 1964. These activities had the goal to define common specifications for medicinal substances and their pharmaceutical preparations, as well as to promote free movement of medicines in the European Union (EU) and the countries of the European Economic Area (EEA). In 1975, a directive by the EC makes compliance with the European Pharmacopoeia Monographs mandatory when requesting marketing authorization for medicines for human use. In 1994, the CoE signed the Ph. Eur. Convention, and the European Network for Official Medicines Control Laboratories (OMCL) was created [6], and its activities organized by EDQM from 1996 onwards. In 2001, EC Directive 2001/83/EC [7] maintains the mandatory character of $\mathrm{Ph}$. Eur. monographs when requesting marketing authorization, superseding all previous directives.

With the task of protecting public health by applying one common compulsory standard in its Member States, the Ph. Eur. is the official pharmacopoeia and legally binding in 37 Member States and the EU. It is complemented by national pharmacopoeias for specific monographs of interest to only one Member State. Ph. Eur. today contains legally binding quality standards for active substances (organic, inorganic), excipients, substances of biological origin and biotechnology, herbal drugs, essential oils and fats, preparations, radiopharmaceuticals, vaccines, sera (human, veterinary), blood derivatives, and homeopathic preparations. These monographs are supplemented by general monographs on dosage forms as well as general texts on quality issues and standard analytical methods. In total, nearly 2,200 monographs currently exist. The first finished product monograph containing a chemically defined active substance (sitagliptin tablets used in type 2 diabetes) was adopted by the Ph. Eur. commission only as recent as March 2015. A second finished product, rosuvastatin tablets, was also added for monograph elaboration to the work programme, taking into account products from multiple manufacturers. In 2016, the EDQM will publish the ninth Edition of the European Pharmacopoeia, which will contain nearly 3,000 monographs and general texts and will become legally binding by 1 January 2017 [8].

The Ph. Eur. Commission (COM) consists of one delegation per each of the 37 members, a delegation from the EU consisting of

A biological medicinal product is a product, the active substance of which is a biological substance. A biological substance is a substance that is produced by or extracted from a biological source and that needs for its characterization and the determination of its quality a combination of physico-chemical-biological testing, together with the production process and its control - definition from Directive 2001/83/EC a representative from Directorate General Health \& Consumer Affairs and the EMA, and observers from 22 countries and WHO. Delegates come from health ministries, health authorities, pharmacopoeias, universities, or industry and are appointed by the national authorities on the basis of their expertise. There are cur-

Figure 1: Introduction of new monographs into Ph. Eur.

Proposal to Ph. Eur. Commission (COM)
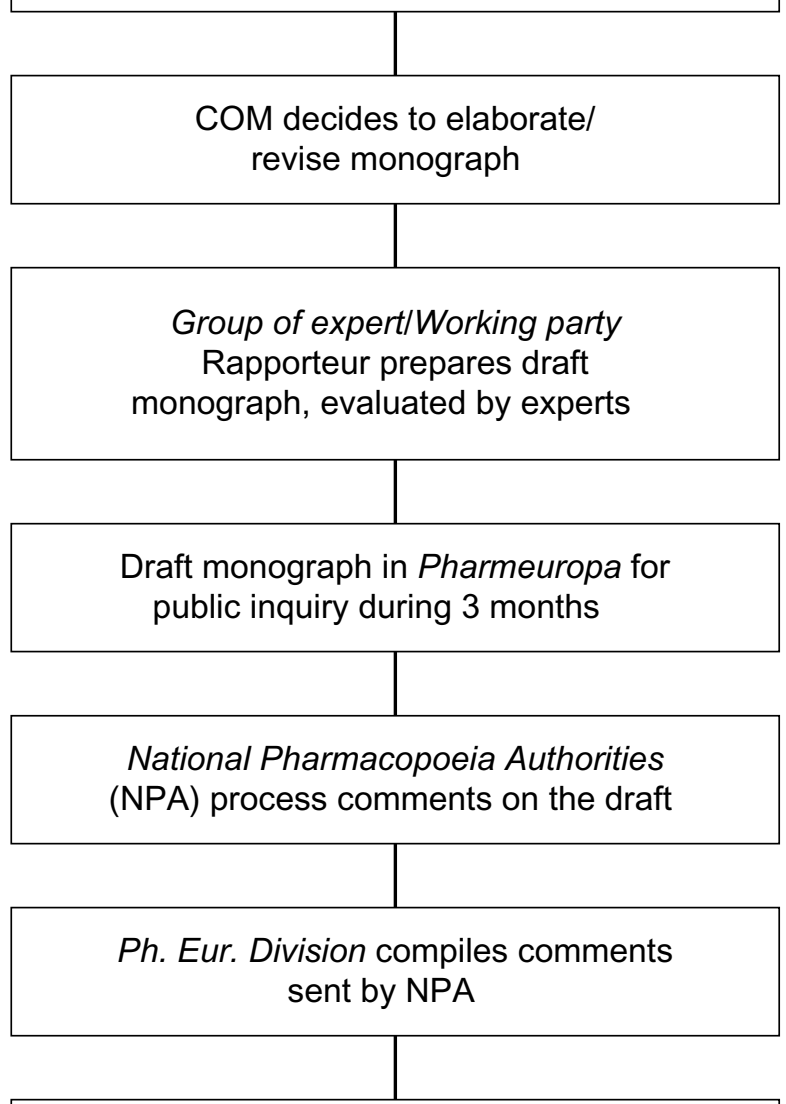

\section{Group of expert/Working party examines comments and revises monograph accordingly}

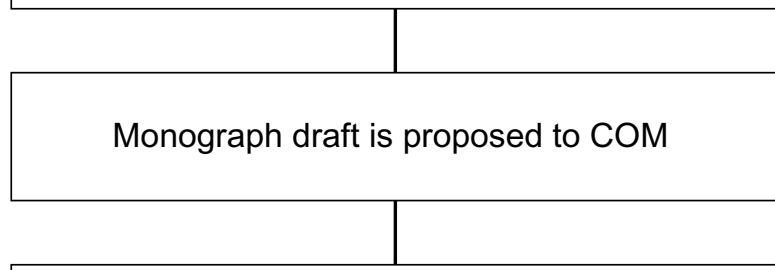

COM adopts monograph and sets the implementation date (ca. one year after adoption) 
rently 20 permanent Groups of Experts and 52 ad-hoc Working Parties dedicated to revising texts that are to be adopted by the COM which also decides on the composition of these groups.

The procedure by which new texts are introduced into Ph. Eur. is depicted in Figure 1.

On submission of a proposal, typically by a national authority of a Member State, the COM decides to have the new monograph elaborated by a group of experts or working party. A draft elaborated by this group is submitted to Pharmeuropa [9], the free online publication of the EDQM for review and comments by interested parties for the duration of three months. The National Pharmacopoeia Authorities (NPA) of the Member States process the received comments on the draft monograph, which are then compiled and resubmitted to the group of experts or working party. On adaptation of the draft according to the comments received, the monograph is proposed to COM, which adopts it and sets the date of implementation into Ph. Eur., where the monograph is published about six months later.

At EDQM, the Non-Biological Complexes (NBC) Working Party was created in 2011 following an initiative of SwissMedic, the Swiss agency responsible for the authorization and supervision of therapeutic products (medicinal products and medical devices). The COM decided to add to its work programme the elaboration of a monograph on Iron Sucrose Concentrated Solution as a first example for NBCDs. Iron sucrose (IS) and its follow-on products, so-called iron sucrose similars (ISSs) products consist of a polynuclear iron core of iron(III)-oxyhydroxide, which is stabilized by a complex coating of sucrose. IS products have been used in parenteral replacement therapy of anaemia, e.g. in chronic kidney disease (CKD) patients on dialysis to stimulate the generation of erythrocytes. ISSs in Europe received marketing authorization through the generic drug pathway, suggesting interchangeability. Clinical reports such as reported in [10], however, have recently shown that IS and ISSs may not have the same or similar efficacy and safety profile, and thus appear not to be interchangeable. A regulatory pathway, comparable to the one applied for biosimilars, is therefore currently discussed as mentioned above.

The working party, consisting of experts from academia, manufacturers and regulatory authorities, is currently in the process of defining, establishing and validating assays for the characterization of iron sucrose concentrated solution to be included in the monograph. The methods considered to be included comprise assays to assess particle size by size exclusion chromatography and differential laser light scattering. The latter will also contribute to the development of a general method on size measurement of nanoparticles currently under discussion. In addition, assays for the measurement of labile iron released from the particles are being developed, as this is recognized as an important parameter for the safety of IS products.

In drafting the monograph, the working party takes into account methods described in existing monographs on Iron Sucrose Injection in the BP and USP. The working party has also participated in commenting on the draft of the EMA reflection paper on the subject of 'data requirements for iron-based nano-colloidal products'.

2. The United States Pharmacopeial Convention (USP)

The USP was founded in 1820 in attendance of delegates of medical societies from several states, creating a list of standards and a national formulary. In 1850, colleges were invited to contribute to the revision of the USP, and in 1888, the first National Formulary (NF) was introduced by the American Pharmacists Association (APhA). USP was incorporated in 1900 in its present form as a not-for-profit organization; it is thus not a governmental organization like the Ph. Eur. The USP and NF standards for strength, quality, purity, packaging and labelling are recognized as official and enforced by FDA from 1938 onwards. In 1977, the scopes of USP and NF are redefined such that standards for drug substances and dosage forms are specified in USP, whereas excipient standards are included in NF. From 1980 onwards, both USP and NF are published under one cover. The USP-NF is also translated into Chinese and Russian. While being a national organization, USP has developed an international presence with offices and laboratory facilities in Hyderabad (India), Shanghai (China) and São Paulo (Brazil). Along with these facilities, USP also runs an office in Basel (Switzerland).

The procedure by which a USP monograph is developed is shown in Figure 2. In contrast to Ph. Eur., where the process is initiated by the submission of a proposal by a national authority, the USP process is driven by a manufacturer of an originator or generic drug sponsoring the proposal. Together with the proposal, the sponsor supplies USP with information on the drug's specifications, relevant assays and test methods. The proposal and data submitted is reviewed by scientific staff of USP, who will also perform laboratory testing. A draft monograph is then submitted to the Council of Experts and one of its Expert Committees for scientific opinion and merits of the proposed monograph. The Council of Experts then decides to publish the draft monograph for a three-month public review at Pharmaceutical Forum (PF), the online peer-reviewed journal of USP [11].

Successively, the comments received are reviewed by the Expert Committee and integrated into the monograph draft. A USP liaison (scientific officer) compiles and analyses these comments and the draft, and submits either for further revision or for publication in USP-NF. The draft thereby becomes an official monograph, the specifications stated in the standard must be abided to when marketing the product within the US.

Besides the development and publication of monographs for prescription and over-the-counter (OTC) drugs (a relatively new activity at USP), the preparation of Reference Standards is a major activity and source of income for USP. The more than 3,500 USP Reference Standards are used in the examination of the identity, strength, quality and purity of drugs, biologicals and excipients, thus contributing to the quality of drug manufacturing. The USP Council of Experts is closely interacting with experts from industry and regulatory agencies. Until 2015, USP has made available a compendium of public standards (Medicines Compendium, $\mathrm{MC})$ for approved medicines on a global basis. The MC monographs were freely available online, providing performance tests for critical quality attributes and acceptance criteria, a sourceindependent Reference Procedure and one or more Acceptable Procedures. The website was discontinued and shall be replaced in the future by a 'collaborative programme' [12].

Concerning activities in the area of NBCDs, and in addition to a published monograph on Iron Sucrose Injection as mentioned 


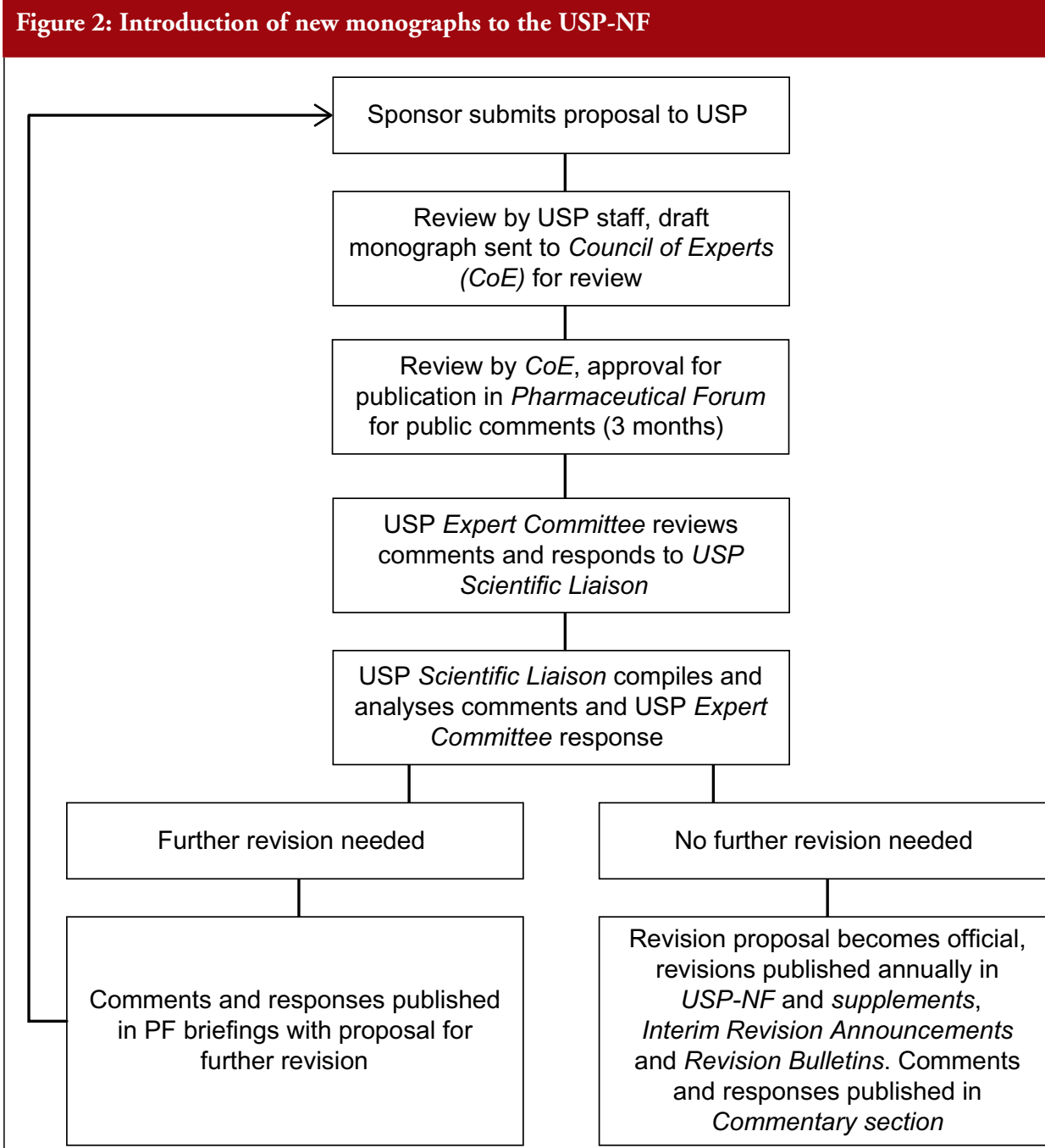

PF: Pharmaceutical Forum; USP-NF: United States Pharmacopeial Convention-National Formulary. profiles of Copaxone ${ }^{\circledR}$ to purported 'generic' glatiramoids, e.g. Glatimer $^{\circledR}$ (India), Probioglat ${ }^{\circledR}$ (Mexico) and Escadra ${ }^{\circledR}$ (Argentina) revealed essential differences between the originator and the follow-on drugs [14,15]. It was therefore suggested by Teva that follow-on glatiramoids should not receive marketing authorization by the generic drug pathway. However, as stated in a Denial Letter [16] to a Citizen's Petition Letter by Teva, FDA insisted that sameness between Copaxone ${ }^{\circledR}$ and a follow-on glatiramoid, Momenta/ Sanofi's Glatopa ${ }^{\circledR}$, can be demonstrated by showing equivalence in the fundamental reaction scheme, the drug's physicochemical properties including composition, structural signatures for polymerization and depolymerization and results in a relevant biological assay. On 15 April 2015, FDA approved Glatopa ${ }^{\circledR}$ [17] as a first generic glatiramoid for the treatment of relapsing MS. Based on these discussions, FDA may issue the draft of a guidance document on glatiramoids in the future.

USP is now in the process of establishing an expert panel to discuss the draft of a monograph on glatiramer acetate. The panel will most likely include experts from academia, regulatory authorities and manufacturers. Major issues to be addressed may include the definition of critical quality attributes for glatiramoids, as well as whether above, USP has engaged in installing an Expert Panel on glatiramers with a call for candidates published on 15 December 2015. Glatiramers (or glatiramoids) are complex drugs consisting of a large number of synthetic polypeptides of four amino acids (glutamic acid, alanine, lysine and tyrosine). Based on studies at the Weizmann Institute in the 1960s and early 1970s, which were aimed at developing experimental autoimmune encephalitis (EAE) in guinea pigs as a model for multiple sclerosis (MS), glatiramoids were shown to protect against EAE. Successively, the first glatiramoid drug for relapsing forms of MS (Copaxone ${ }^{\circledR}$ ) was developed and marketed by Teva Pharmaceuticals (Teva).

As is the case for biological complex drugs, the inherent complexity of glatiramoids requires a very well controlled manufacturing process ('the process is the product'). In fact, by slight alteration of the manufacturing process, Teva had produced a glatiramoid (TV5010) that was similar in terms of amino acid ratio and physical properties [13] to Copaxone ${ }^{\circledR}$. While good safety and tolerability in patients treated with TV-5010 was shown, long-term toxicity studies in rats and monkeys revealed the occurrence of fibrosis in rats and eosinophilia in monkeys. Studies comparing gene expression bioassays should be included in the monograph to show activity and safety.

\section{International harmonization: ICH and PDG}

The International Council for Harmonisation of Technical Requirements for Pharmaceuticals for Human Use (ICH) was launched in 1990 at Brussels headquarters of EFPIA (European Federation of Pharmaceutical Industries and Associations) in the presence of representatives from regulatory agencies of Europe, Japan greater harmonization in regulatory requirements for pharmaceutical product registration [18]. Such harmonization would result in the avoidance of the repetition of studies in the research and development of new human medicines. During the last 25 years, $\mathrm{ICH}$ has established harmonized technical requirements for the quality, safety and efficacy of new medicines in EU, Japan and the US.

$\mathrm{ICH}$ is governed by its Steering Committee (SC), which is composed of representatives from the European Commission, EFPIA, the Japanese Ministry of Health, Labour and Welfare and the US, and from industry. The mission of ICH is to achieve 
(MHLW), the Japan Pharmaceutical Manufacturers Association (JPMA), FDA, Pharmaceutical Research and Manufacturers of America (PhRMA), Swissmedic, and Health Canada. WHO is an Observer to the SC, and the International Federation of Pharmaceutical Manufacturers and Associations (IFPMA) participates as a non-voting member of the SC. The involvement of EDQM in ICH activities is given through the SC membership of the EC.

The ICH SC has several activities. It has established a structure to develop the Medical Dictionary for Regulatory Activities (MedDRA) to facilitate sharing of regulatory information internationally for human medicines (pharmaceuticals, biologicals, vaccines and drug-device combination products). MedDRA is available for use in registration, documentation and safety monitoring of medical products both before and after marketing authorization.

SC has appointed Working Groups to review the differences in requirements between EU, Japan and the US and develop the scientific consensus required to reconcile those differences. The four types of ICH working groups include Expert Working Groups (EWG) charged with developing a harmonized guideline, Implementation Working Group that develops Q \& As to facilitate implementation of existing guidelines, Informal Working Groups having the objective of developing/finalizing a Concept Paper, as well as developing a business plan for harmonization activities, and Discussion Groups dedicated to discuss specific scientific considerations or views. ICH convenes twice a year with the location of meetings rotating among Europe, Japan and the US. The five-step harmonization process is initiated by endorsement of a concept paper and business plan by the SC [19].

Several ICH guidelines are suggested for stability testing of nanomedicines [20], e.g. guideline for stability testing of nontargeted nanomedicines (Q1A (R2)) [21], new dosage forms (Q1C) [22] and biotechnology-based drug products (Q5C) [23] for targeted nanomedicines including a biological targeting moiety such as an antibody. Stability studies of liposomal formulations following ICH guidelines have been reported in literature [24]. A range of methods for testing nanotoxicology has recently been reviewed [25]. It has been suggested that the ICH-S6 guideline [26] may be applied for non-targeted nanoparticles, whereas the ICH-S8 guideline [27] may be applied for the assessment of toxicity of targeted nanoparticles conjugated to biological targeting moieties.

The Pharmacopoeial Discussion Group (PDG) [28] was formed in 1989 with representatives of EDQM, MHLW representing the Japanese Pharmacopoeia (JP), and the USP. WHO has PDG observer status since May 2001. PDG generally meets twice a year. Main activities of PDG are retrospective harmonization of general chapters and excipients monographs of the major pharmacopoeias in the three regions, serving also the mission of ICH. In some cases full harmonization of an entire monograph may not be possible. In such case, only harmonizable elements of the monograph are harmonized (harmonization by attribute). Such monograph for a drug harmonized by attribute, interchangeability is compiled only with respect to the harmonized elements, whereas for non-harmonized attributes, compliance with the individual pharmacopoeial requirements in each region is necessary. From 2003 to 2010, the ICH SC nominated an EWG with members from the three pharmacopoeias to discuss several general test chapters in the respective pharmacopoeias in connection with the ICH Q6 A [29] guideline.

The Q6A guideline has the purpose to help select common test procedures and acceptance criteria for new drug substances of chemical origin and new drug products not previously registered in the EU, Japan and the US. The guideline does not apply to the clinical test phase, but only to the marketing approval process of new drug products and combinations thereof. The guideline specifically mentions drugs such as low molecular weight peptides and (semi)synthetic antibiotics. Not covered, however, are radiopharmaceuticals and oligonucleotide-based drugs.

\section{Summary}

Increasing awareness of the intricacies of NBCDs in the science and regulatory communities was bound to have an effect on drafting of pharmacopoeial content in the form of monographs and general guidelines. Already existing content should be reviewed and revised according to the changing understanding of these complex drugs. International harmonization of pharmacopoeial contents to maintain drug quality, efficacy and safety in the three major areas will be possible through the networks (ICH, PDG) in place today.

Competing interests: The author declares that he is a member of the steering committee of the NBCD Working Group, hosted at the non-profit organization Lygature - formerly known as Top Institute Pharma, Leiden, The Netherlands (www.lygature.org/nbcd).

Provenance and peer review: Commissioned; externally peer reviewed.

\section{References}

1. European Medicines Agency. Guidelines on similar biological medicinal products containing biotechnology-derived proteins as active substance: non-clinical and clinical issues. EMEA/CHMP/BMWP/42832/2005 Rev1. 22 February 2006 [homepage on the Internet]. [cited 2016 Mar 22]. Available from: http://www. ema.europa.eu/docs/en_GB/document_library/Scientific_guideline/2009/09/ WC500003920.pdf

2. Duncan R, Gaspar R. Nanomedicines under the microscope. Mol Pharm. 2011;8(6):2101-41.

3. Borchard G, Flühmann B, Mühlebach S. Nanoparticle iron medicinal products requirements for approval of intended copies of non-biological complex drugs (NBCD) and the importance of clinical comparative studies. Regul Toxicol Pharmacol. 2012;64(2):324-8.

4. U.S. Food and Drug Administration. Evaluate the therapeutic equivalence of generic sodium ferric gluconate iron complex Nulecit ${ }^{\mathrm{TM}}$ and its RLD Ferrlecit ${ }^{\circledR}$. 16 Jul 2013 [homepage on the Internet]. [cited 2016 Mar 22]. Available from: https://www.fbo.gov/spg/HHS/FDA/DCASC/FDA-SOL-1120929/listing. html

5. Council of Europe. Chart of signatures and ratifications of Treaty 050 [homepage on the Internet]. [cited 2016 Mar 22]. Available from: http://www.coe. int/en/web/conventions/full-list/-/conventions/treaty/050

6. European Directorate for the Quality of Medicines \& Healthcare. General European OMCL Network (GEON) [homepage on the Internet]. [cited 2016 Mar 22]. Available from: https://www.edqm.eu/en/General-european-OMCLnetwork-46.html 
7. Directive 2001/83/EC of the European Parliament and of the Council of 6 November 2001 on the Community code relating to medicinal products for human use. Eur-Lex. L-311, 28.11.2001, pp. 67-128.

8. European Directorate for the Quality of Medicines \& Healthcare. Join the Ph. Eur. network! CALL FOR EXPERTS: Appointment of experts to prepare for the 10th Edition. 17 February 2016 [homepage on the Internet]. [cited 2016 Mar 22]. Available from: https://www.edqm.eu/en/news/ join-ph-eur-network-call-experts-appointment-experts-prepare-10th-edition

9. European Directorate for the Quality of Medicines \& Healthcare. Pharmeuropa, Pharmeuropa Bio \& Scientific Notes [homepage on the Internet]. [cited 2016 Mar 22]. Available from: https://www.edqm.eu/en/pharmeuropa-bioand-scientific-notes-584.html

10. Rottembourg J, Kadri A, Leonard E, Dansaert A, Lafuma A. Do two intravenous iron sucrose preparations have the same efficacy? Nephrol Dial Transplant. 2011;26(10): 3262-7.

11. U.S. Pharmacopeial Convention. Pharmacopeial Forum (PF) [homepage on the Internet]. [cited 2016 Mar 22]. Available from: www.usp.org/usp-nf/ pharmacopeial-forum

12. U.S. Pharmacopeial Convention. Medicines Compendium [homepage on the Internet]. [cited 2016 Mar 22]. Available from: http://www.usp.org/global/ medicines-compendium

13. Ramot Y, Rosenstock M, Klinger E, Bursztyn D, Nyska A, Shinar DM. Comparative long-term preclinical safety evaluation of two glatiramoid compounds (glatiramer Acetate, Copaxone(R), and TV-5010, protiramer) in rats and monkeys. Toxicol Pathol. 2012;40(1):40-54.

14. Conner J. Glatiramer acetate and therapeutic peptide vaccines for multiple sclerosis. J Autoimmun Cell Responses. 2014.

15. Towfic F, Funt JM, Fowler KD, Bakshi S, Blaugrund E, Artyomov MN, et al. Comparing the biological impact of glatiramer acetate with the biological impact of a generic. PLOS One. 2014;9(1):e83757.

16. U.S. Food and Drug administration Docket No. FDA-2015-P-1050 [homepage on the Internet]. [cited 2016 Mar 22]. Available from: http://www.fda.gov/ RegulatoryInformation/Dockets/default.htm

17. U.S. Food and Drug administration. FDA approves first generic Copaxone to treat multiple sclerosis. 16 April 2016 [homepage on the Internet]. [cited 2016 Mar 22]. www.fda.gov/NewsEvents/Newsroom/PressAnnouncements/ ucm $443143 . h t m$

18. The International Council for Harmonisation of Technical Requirements for Pharmaceuticals for Human Use [homepage on the Internet]. [cited 2016 Mar 22]. Available from: www.ich.org

19. The International Council for Harmonisation of Technical Requirements for Pharmaceuticals for Human Use. Formal ICH procedure [homepage on the
Internet]. [cited 2016 Mar 22]. Available from: http://www.ich.org/about/ process-of-harmonisation/formalproc.html\#step-1

20. Muthu MS, Feng SS. Pharmaceutical stability aspects of nanomedicines. Nanomedicine (Lond). 2009; 4(8):857-60.

21. European Medicines Agency. ICH Topic Q 1 A (R2). Stability testing of new drug substances and products. CPMP/ICH/2736/99. August 2003 [homepage on the Internet]. [cited 2016 Mar 22]. Available from: http://www.ema.europa.eu/docs/ en_GB/document_library/Scientific_guideline/2009/09/WC500002651.pdf

22. European Medicines Agency. ICH Topic Q 1 C. Stability testing for new dosage forms. CPMP/ICH/280/95. January 1998 [homepage on the Internet]. [cited 2016 Mar 22]. Available from: http://www.ema.europa.eu/docs/en_GB/ document_library/Scientific_guideline/2009/09/WC50

23. European Medicines Agency. ICH Q 5 C. Quality of biotechnological products: stability testing of biotechnological/biological products. CPMP/ ICH/138/95. July 1996 [homepage on the Internet]. [cited 2016 Mar 22]. Available from: http://www.ema.europa.eu/docs/en_GB/document_library/ Scientific_guideline/2009/09/WC500002803.pdf

24. Vorauer-Uhl K, Wagner A, Katinger H. Long term stability of rh-Cu/Zn-superoxide dismutase (SOD)-liposomes prepared by the cross-flow injection technique following International Conference on Harmonisation (ICH) guidelines. Eur J Pharm Biopharm. 2002;54:83-7.

25. Dobrovolskaia MA, Germolec DR, Weaver JI. Evaluation of nanoparticle immunotoxicity. Nature Nanotechnol. 2009;4:411-4.

26. ICH guideline S6 (R1) - preclinical safety evaluation of biotechnology-derived pharmaceuticals. EMA/CHMP/ICH/731268/1998 [homepage on the Internet]. [cited 2016 Mar 22]. Available from: http://www.ema.europa.eu/docs/en_GB/ document_library/Scientific_guideline/2009/09/WC500002828.pdf

27. European Medicines Agency. ICH Topic S 8. Immunotoxicity studies for human pharmaceuticals. EMEA/CHMP/167235/2004. May 2006 [homepage on the Internet]. [cited 2016 Mar 22]. Available from: http://www.ema.europa.eu/docs/ en_GB/document_library/Scientific_guideline/2009/09/WC500002851.pdf

28. European Directorate for the Quality of Medicines \& Healthcare. Working procedures of the Pharmacopoeial Discussion Group (PDG) [homepage on the Internet]. [cited 2016 Mar 22]. Available from: https://www.edqm.eu/ medias/fichiers/Working_Procedures_of_the_PDG.pdf

29. European Medicines Agency. ICH Topic Q 6 A. Specifications: test procedures and acceptance criteria for new drug substances and new drug products: chemical substances. CPMP/ICH/367/96. May 2000 [homepage on the Internet]. [cited 2016 Mar 22]. Available from: http://www.ema.europa.eu/docs/ en_GB/document_library/Scientific_guideline/2009/09/WC500002823.pdf

DOI: 10.5639/gabij.2016.0501.009

Copyright $\odot 2016$ Pro Pharma Communications International 